\title{
Laparoscopic Appendectomy Outcomes on the Weekend and During the Week are no Different: A National Study of 151,774 Patients
}

\author{
Mathias Worni - Truls Østbye • Mihir Gandhi • \\ Dimple Rajgor · Jatin Shah - Anand Shah - Ricardo Pietrobon • \\ Danny O. Jacobs $\cdot$ Ulrich Guller
}

Published online: 13 March 2012

(c) Société Internationale de Chirurgie 2012

\begin{abstract}
Background The "weekend effect" is defined as increased morbidity and mortality for patients admitted on weekends compared with weekdays. It has been observed for several diseases, including myocardial infarction and renal insufficiency; however, it has not yet been investigated for laparoscopic appendectomy in acute appendicitis-one of the most prevalent surgical diagnoses.
\end{abstract}

This work was in part presented at the Annual Congress of the Swiss Society for Surgery, Geneva/Switzerland, May 26, 2011.

M. Worni - M. Gandhi - D. Rajgor · J. Shah · A. Shah ·

R. Pietrobon

Research on Research Group, Department of Surgery,

Duke University Medical Center, Durham, NC, USA

M. Worni · U. Guller $(\bowtie)$

Department of Visceral Surgery and Medicine, Inselspital,

Berne University Hospital, 3010 Berne, Switzerland

e-mail: ulrich.guller@gmail.com

T. Østbye

Department of Community and Family Medicine,

Duke University Medical Center, Durham, NC, USA

T. Østbye $\cdot$ M. Gandhi

Duke-NUS Graduate Medical School, Singapore, Singapore

M. Gandhi

Singapore Clinical Research Institute, Singapore, Singapore

D. O. Jacobs

Department of Surgery, Duke University Medical Center, Durham, NC, USA

U. Guller

Department of Medical Oncology \& Hematology, Kantonal Hospital St. Gallen, 9007 St. Gallen, Switzerland
Methods The present study is based on the Nationwide Inpatient Sample (NIS) from 1999 to 2008. The following outcomes were compared between patients undergoing laparoscopic appendectomy for acute appendicitis admitted on weekdays versus weekends: severity of appendicitis, intraoperative and postoperative complications, conversion rate, in-hospital mortality, and length of hospital stay. Unadjusted and risk-adjusted generalized linear regression analyses were performed.

Results Overall, 151,774 patients were included, mean age was 39.6 years, $52.6 \%(n=79,801)$ were male, and $25.3 \%$ ( $n=38,317)$ were admitted on weekends. After risk adjustment, the conversion rate was lower [odds ratio (OR): $0.94, p=0.004$, number needed to harm $(\mathrm{NNH})$ : 244], whereas pulmonary complications (OR: 1.12, $p=0.028$, NNH: 649) and reoperations (OR: 1.21, $p=0.013$, NNH: 1,028 ) were slightly higher on weekends than on weekdays. Overall postoperative complications (OR: $1.03, p=0.24)$, mortality (OR: $1.37, p=0.075)$ and length of hospital stay (mean on weekday: 2.00 days, weekends: 2.01 days, $p=0.29$ ) were not statistically different.

Conclusions The present investigation provides evidence that no clinically significant "weekend effect" for patients undergoing laparoscopic appendectomy exists. Therefore, hospital or staffing policy changes are not justified based on the findings from this large national study.

\section{Introduction}

Acute appendicitis is the most frequent emergent abdominal operation performed in the United States, with approximately 326,000 operations per year [1]. Although cases with acute appendicitis are evenly distributed 
throughout the week [2], routine care in hospitals is only provided on weekdays [3, 4]. On weekends, hospitals cater only emergency care due to reduced staffing, including availability of surgical expertise [5], which may lead to inferior patient outcomes. Although reduced availability could theoretically lead to inferior patient outcomes, the impact of the weekend admission on short-term outcomes of laparoscopic appendectomy for acute appendicitis has not previously been reported.

For multiple other acute conditions, the outcomes of patients admitted to the emergency room on weekends are reported to be worse than for those admitted during weekdays [6-12]. This outcome difference is known as the "weekend effect" [11]. One reason for inferior outcomes on weekends might be the delay from onset of symptoms to diagnostic interventions and treatment $[6,7,10,13-15]$. Treatment delay has been shown to increase morbidity and length of hospital stay for patients undergoing appendectomy after acute appendicitis in some studies [16, 17], although other studies did not support those findings [18-20]. For a highly prevalent disease, such as acute appendicitis, even relatively small adverse short-term outcome differences between weekday and weekend admissions could be of great clinical, administrative, and cost relevance. Detecting potentially avoidable outcome differences in a time of rising pressure on healthcare costs is of major importance to a public health service. On the other hand, it is crucial to confirm that no clinically important differences exist, because it will avoid unnecessary and potentially expensive hospital and staffing changes.

We undertook an analysis of a population-based administrative database to compare the short-term outcomes of patients admitted on weekends with those for patients admitted on weekdays for acute appendicitis and subsequently undergoing laparoscopic appendectomy. We hypothesized that patients with acute appendicitis admitted on weekends would have worse outcomes compared with those admitted on weekdays.

\section{Methods}

We obtained approval from the Institutional Review Board at Duke University Medical Center before initiating this study. We used prospectively collected data from the Nationwide Inpatient Sample (NIS) from 1999 to 2008. The NIS is part of the Healthcare Cost and Utilization Project sponsored by the Agency for Healthcare Research and Quality. In the United States, it is the largest all-payer inpatient care database that is publicly available. It contains approximately 5-8 million records of patient discharges from a sample of approximately 1,000 hospitals in the United States. The NIS is a stratified sample of community hospitals in the United States. The five following sampling strata are used to achieve maximal representation of U.S. hospitals: geographic region (northeast, north central, west, and south), location (urban and rural), teaching status (teaching and nonteaching hospital), ownership (public, private not-for-profit, and private investor-owned), and bed size (small, medium, and large). This allows for the generalization of results to the entire population of the United States. The International Classification of Diseases, Ninth Revision, Clinical Modification (ICD-9-CM) was used for identification of procedures and diagnosis.

All patients aged 18 years and older who underwent laparoscopic appendectomy for acute appendicitis were included. Patients were identified from the NIS dataset through ICD-9-CM diagnosis codes for acute appendicitis (540 and 540.9: acute appendicitis without perforation or abscess, 540.0: acute appendicitis with perforation, 540.1: acute appendicitis with abscess) and for the primary procedure code for laparoscopic appendectomy (47.01). We also included patients who underwent open appendectomy (47.09) but for whom the primary procedure was laparoscopic appendectomy and who subsequently were converted to open surgery (V64.4 or V61.41). Patients with the diagnosis of chronic inflammatory bowel disease (555.0-556.9) and patients who were not admitted on an urgent or emergency basis were excluded from our analysis.

The severity of acute appendicitis was grouped into two categories: (1) uncomplicated (ICD-9-CM: 540, 540.9) and (2) complicated appendicitis $(540.0,540.1)$. We assessed intraoperative and postoperative in-hospital complications through ICD-9-CM codes. Those complications were categorized into seven mutually exclusive groups, as described by Guller et al. [21]: (1) mechanical wound complications, (2) infections, (3) urinary/renal complications, (4) pulmonary complications, (5) gastrointestinal complications, (6) cardiovascular complications, and (7) systemic complications. Conversion from laparoscopic to open appendectomy was identified through the following ICD-9-CM diagnosis codes: V64.4 and V64.41. Complications after hospital discharge were not possible to ascertain due to the fact that NIS only includes inpatient data. We also extracted data to measure in-hospital mortality, rate of routine discharge (routine vs. nonroutine), length of hospital stay (measured in days from admission to discharge: discharge at the same day as admission coded as 0 ), and time from admission to surgery (days).

Differentiating between weekday and weekend admission is possible by using a variable in the NIS database that provides this information for all patients included in the dataset. Weekend admission is defined as admission on either Saturday or Sunday and is calculated from the original admission date [22]. 
As covariates, we included age, gender, race (Caucasian, African American, Hispanic, and other), ZIP-related household income in three categories (1: \$1-34,999, 2: \$35,000-44,999, 3: \$45,000), insurance status (Medicare, Medicaid, private including health maintenance organization (HMO), others), Charlson comorbidity index modified by Deyo et al. [23, 24], hospital location/teaching status (rural, urban nonteaching, urban teaching), hospital region (northeast, midwest, west, south), hospital volume (in quartiles), and degree of appendicitis (uncomplicated, complicated).

\section{Statistical methods}

Differences in baseline sociodemographic and hospital characteristics and comorbidity variables among patients admitted for acute appendicitis on a weekday or the weekend were tested using $t$ tests and chi-square tests as appropriate. Comparisons of the time from admission to surgery between patients admitted on weekdays and those admitted on weekends were performed using the Wilcoxon rank-sum test. Univariate analyses were first performed. Multivariable logistic regression models were then used to assess the risk-adjusted impact of admission day (weekday vs. weekend) on intraoperative and postoperative complications (overall and for specific subsets), mortality, and discharge status. For better assessment of clinical relevance, numbers needed to harm (NNH) as well as $95 \%$ confidence intervals were calculated for all significant results. The effect of admission day on length of hospital stay was assessed using multiple linear regression analysis. Since the distribution of length of hospital stay was highly right-skewed, analyses were performed on log-transformed data. The presented estimates are retransformed values. Because race was unavailable for $24.5 \%$ of patients, it was not included as a covariate in the final multivariate model presented. Sensitivity analyses, including race in the multivariate model, resulted in no significant differences compared with the final model presented. Level of statistical significance was set to $p<0.05$ for all analytical steps and all tests were two-sided. The statistical analyses were performed using Stata/SE version 10 (Stata Corporation, College Station, TX, USA).

\section{Results}

The NIS includes 151,774 patients for the years 1999-2008 who underwent laparoscopic appendectomy (including conversion to an open appendectomy) for acute appendicitis. Of them, $113,457(74.75 \%)$ patients were admitted to the hospital on weekdays and 38,317 (25.25\%) patients were admitted on weekends.
The mean age of the patients was 39.6 [standard deviation (SD) 15.9] years. Overall, $52.6 \%$ of patients were male and $64.2 \%$ had private insurance. Most of the patients had a Deyo-Score of $0(88.6 \%)$. Patients admitted on weekdays were more likely to be white (weekday: $54.4 \%$, weekend: $53 \%$ ), have private insurance (weekday: $64.8 \%$, weekend: $62.6 \%$ private), and have higher incomes (weekday: $52.8 \%$ high ZIP-income, weekend: $51.6 \%$ high ZIP-income; Table 1).

No significant difference was detected in severity of appendicitis between weekday and weekend admission. Complicated appendicitis was present in $24.9 \%$ of the patients in both groups. The mean time from admission to surgery was 0.233 days (SD 1.22) for patients admitted on weekdays and 0.236 days (SD 2.07) for patients admitted on weekends $(p=0.08)$. Intraoperative complications did not differ between patients admitted on weekdays or weekends, including injury to adjacent structures, retained foreign bodies, and intraoperative hemorrhage (Table 2).

Table 1 Demographic characteristics of patients undergoing laparoscopic appendectomy between 1999 and 2008

\begin{tabular}{|c|c|c|c|}
\hline & $\begin{array}{l}\text { Weekdays } \\
(n=113,457 \\
74.75 \%)\end{array}$ & $\begin{array}{l}\text { Weekend } \\
(n=38,317, \\
25.25 \%)\end{array}$ & $p$ value \\
\hline Age mean (SD) & $39.56(15.80)$ & 39.54 (15.99) & 0.77 \\
\hline \multicolumn{4}{|l|}{ Gender } \\
\hline Female & $53,781(47.40)$ & $18,186(47.46)$ & 0.84 \\
\hline Male & $59,672(52.59)$ & $20,129(52.53)$ & \\
\hline Unknown & $4(0)$ & $2(0.01)$ & \\
\hline \multicolumn{4}{|l|}{ Race } \\
\hline Caucasian & $61,712(54.39)$ & $20,323(53.04)$ & $<0.001$ \\
\hline African American & $5,626(4.96)$ & $1,950(5.09)$ & \\
\hline Hispanic & $12,780(11.26)$ & $4,561(11.90)$ & \\
\hline Other & $5,616(4.95)$ & $1,989(5.19)$ & \\
\hline Unknown & $27,723(24.43)$ & $9,494(24.78)$ & \\
\hline \multicolumn{4}{|l|}{ Insurance } \\
\hline Medicare & $10,270(9.05)$ & $3,659(9.55)$ & $<0.001$ \\
\hline Medicaid & $9,057(7.98)$ & $3,259(8.51)$ & \\
\hline $\begin{array}{l}\text { Private including } \\
\text { HMO }\end{array}$ & $73,499(64.78)$ & $23,987(62.60)$ & \\
\hline Self-pay/other & $20,356(17.94)$ & $7,324(19.11)$ & \\
\hline Unknown & $275(0.24)$ & $88(0.23)$ & \\
\hline \multicolumn{4}{|c|}{ ZIP code-related income } \\
\hline $1-34,999$ & $23,653(20.85)$ & $8,250(21.53)$ & 0.001 \\
\hline $35,000-44,999$ & $27,418(24.17)$ & $9,344(24.39)$ & \\
\hline$\geq 45,000$ & $59,895(52.79)$ & $19,770(51.6)$ & \\
\hline Unknown & $2,491(2.20)$ & $953(2.49)$ & \\
\hline \multicolumn{4}{|l|}{ Hospital } \\
\hline Rural & $13,419(11.83)$ & $4,625(12.07)$ & 0.41 \\
\hline Urban nonteaching & $54.687(48.2)$ & $18,373(47.95)$ & \\
\hline
\end{tabular}


Table 1 continued

\begin{tabular}{|c|c|c|c|}
\hline & $\begin{array}{l}\text { Weekdays } \\
(n=113,457 \\
74.75 \%)\end{array}$ & $\begin{array}{l}\text { Weekend } \\
(n=38,317, \\
25.25 \%)\end{array}$ & $p$ value \\
\hline Urban teaching & $45,270(39.9)$ & $15,289(39.9)$ & \\
\hline Unknown & $81(0.07)$ & $30(0.08)$ & \\
\hline \multicolumn{4}{|l|}{ Hospital region } \\
\hline Northeast & $25,920(22.85)$ & 8,118 (21.19) & $<0.001$ \\
\hline Midwest & $23,634(20.83)$ & $8,121(21.19)$ & \\
\hline West & $48,221(42.5)$ & $16,598(43.32)$ & \\
\hline South & $15,682(13.82)$ & $5,480(14.3)$ & \\
\hline \multicolumn{4}{|l|}{ Hospital volume } \\
\hline Quartile I & $28,482(25.1)$ & $9,504(24.8)$ & 0.014 \\
\hline Quartile II & $28,928(25.5)$ & $9,980(26.05)$ & \\
\hline Quartile III & $27,913(24.6)$ & $9,572(24.98)$ & \\
\hline Quartile IV & $28,134(24.8)$ & $9,261(24.17)$ & \\
\hline \multicolumn{4}{|l|}{ Deyo score } \\
\hline 0 & $100,485(88.57)$ & $33,995(88.72)$ & 0.7 \\
\hline 1 & $6,415(5.65)$ & $2,144(5.6)$ & \\
\hline$>1$ & $6,557(5.78)$ & $2,178(5.68)$ & \\
\hline \multicolumn{4}{|l|}{ Year of operation } \\
\hline 1999 & $2,449(75.45)$ & $797(24.55)$ & $<0.001$ \\
\hline 2000 & $3,356(75.01)$ & $1,118(24.99)$ & \\
\hline 2001 & $3,451(74.31)$ & $1,193(25.69)$ & \\
\hline 2002 & $9,656(74.77)$ & $3,259(25.23)$ & \\
\hline 2003 & 11,643 (74.26) & $4,036(25.74)$ & \\
\hline 2004 & $12,689(75.46)$ & $4,126(24.54)$ & \\
\hline 2005 & $14,827(75.69)$ & $4,763(24.31)$ & \\
\hline 2006 & $16,684(74.79)$ & $5,625(25.21)$ & \\
\hline 2007 & $17,811(73.68)$ & $6,362(26.32)$ & \\
\hline 2008 & $20,891(74.8)$ & $7,038(25.2)$ & \\
\hline
\end{tabular}

Values are number $(n)$ and $\%$ if not otherwise indicated. $P$ values are given as $t$ test and $\chi^{2}$ test where appropriate. Percentages for year of operation are calculated on an annual basis

Due to rounding not all percentages add up to $100 \%$

Conversion rate from laparoscopic to open procedure was higher in patients who underwent laparoscopic appendectomy on weekdays $(8.06 \%)$ than on weekends $(7.65 \%$; $p=0.01$; NNH: 244).

For univariate analyses, admission on weekends was associated with higher in-hospital mortality (weekday: $0.09 \%$, weekend: $0.13 \%, p=0.043$ ) and with more pulmonary complications (weekday: $1.33 \%$, weekend: $1.48 \%$, $p=0.025$ ). There was a higher reoperation rate for patients being operated on weekends $(0.64 \%)$ than on weekdays $(0.55 \%, p=0.029)$. All other clinical postoperative short-term outcomes did not differ between the two groups in univariate analysis (Table 2). There was no difference in unadjusted mean length of hospital stay between the two groups (weekday: 2.00 days, 95\% confidence interval (CI): 1.99-2.01; weekend: 2.01 days; $95 \% \mathrm{CI}$ : $2.00-2.03 ; p=0.28$ ).

After adjusting for multiple covariates, there was no difference in severity of appendicitis and intraoperative complications (Table 2). Among the seven categories of postoperative adverse outcomes (Table 2), there was only a higher odds of pulmonary complications present in patients who underwent laparoscopic appendectomy on weekends (OR: $1.12,95 \%$ CI: $1.01-1.24 ; p=0.028$, NNH: 649). No other complications, including overall intraoperative complications, showed any difference. Patients admitted on weekends had a higher risk of reoperation than patients admitted on weekdays (OR: 1.21, 95\% CI: 1.04-1.41; $p=0.013$, NNH: 1,028) and there was a trend toward a significant increase for in-hospital mortality (OR: 1.37, 95\% CI: $0.97-1.94 ; p=0.075)$. Finally, the length of hospital stay did not differ between the two groups (weekday: 2.00 days, 95\% CI: 1.99-2.01; weekend: 2.01 days, $95 \%$ CI: $2.00-2.02 ; p=0.29$ ).

\section{Discussion}

This is the first investigation to assess a "weekend effect" for patients who underwent laparoscopic appendectomy for acute appendicitis. Using the NIS database, we demonstrated that there is no clinically significant weekend effect for patients who undergo laparoscopic appendectomy for acute appendicitis. Patients admitted on the weekend had a slightly higher rate of pulmonary complications and increased reoperation rate, as well as lower conversion rate compared with those admitted on weekdays. However, the absolute outcome differences between weekend versus weekday admissions are very small, resulting in very large numbers needed to harm and therefore are of negligible clinical relevance.

We also detected a trend toward increased in-hospital mortality for patients admitted on weekends. Nearly 10 years ago, Bell and Redelmeier [6] performed a retrospective analysis of 4 million acute care admissions in Ontario, Canada. They found that admission on weekends was associated with increased mortality rates compared with weekday admission in 23 of 100 different diagnoses. The underlying diseases were diverse, ranging from ruptured abdominal aneurysm to leukemia. Since 2001, several investigations have led to different conclusions regarding the "weekend effect." Weekend admission has been associated with higher mortality in acute kidney injury [8], uterine cancer, duodenal ulcer, cardiovascular symptoms [11], upper gastrointestinal hemorrhage [10], intracerebral hemorrhage [12], and peptic ulcer disease [15]. On the other hand, no difference in mortality was demonstrated in patients with subarachnoidal hemorrhage 
Table 2 Unadjusted and adjusted in-hospital complications for patients undergoing laparoscopic appendectomy on weekdays versus weekends

\begin{tabular}{|c|c|c|c|c|c|c|c|}
\hline & $\begin{array}{l}\text { Weekday } \\
(n=113,457, \\
74.75 \%)\end{array}$ & $\begin{array}{l}\text { Weekend } \\
(n=38,317, \\
25.25 \%)\end{array}$ & $\begin{array}{l}\text { Unadjusted } \\
\text { analysis } \\
(\mathrm{OR}, 95 \% \mathrm{CI})\end{array}$ & $p$ value & $\begin{array}{l}\text { Adjusted analysis } \\
\text { (OR, 95\% CI) }\end{array}$ & $p$ value & NNH $(95 \% \mathrm{CI})$ \\
\hline \multicolumn{8}{|c|}{ Severity of appendicitis $(n, \%)$} \\
\hline Uncomplicated & $85,245(75.13)$ & $28,789(75.13)$ & Ref. & & Ref. & & \\
\hline Complicated & $28,212(24.87)$ & $9,528(24.87)$ & $1.00(0.97-1.03)$ & 1.00 & $0.99(0.96-1.02)$ & 0.59 & \\
\hline Conversion rate & $9,142(8.06)$ & $2,930(7.65)$ & $0.94(0.9-0.99)$ & 0.01 & $0.94(0.89-0.98)$ & 0.004 & 244 (139-987) \\
\hline \multicolumn{8}{|c|}{ Intraoperative complications } \\
\hline $\begin{array}{l}\text { Injury to } \\
\text { adjacent } \\
\text { structures }\end{array}$ & $473(0.42)$ & $152(0.4)$ & $0.95(0.79-1.14)$ & 0.59 & $0.96(0.79-1.15)$ & 0.64 & \\
\hline $\begin{array}{l}\text { Retained foreign } \\
\text { body }\end{array}$ & $7(0.01)$ & $1(0)$ & $0.42(0.05-3.44)$ & 0.42 & NA & & \\
\hline $\begin{array}{l}\text { Hemorrhage } \\
\text { complication }\end{array}$ & $481(0.42)$ & $164(0.43)$ & $1.01(0.85-1.21)$ & 0.92 & $1.02(0.85-1.22)$ & 0.85 & \\
\hline $\begin{array}{l}\text { Any intraoperative } \\
\text { complication }\end{array}$ & $931(0.82)$ & $311(0.81)$ & $0.99(0.87-1.13)$ & 0.88 & $1.00(0.87-1.14)$ & 0.96 & \\
\hline \multicolumn{8}{|c|}{ Postoperative in hospital complications } \\
\hline $\begin{array}{l}\text { Mechanical } \\
\text { wound } \\
\text { complications }\end{array}$ & $446(0.39)$ & $147(0.38)$ & $0.98(0.81-1.18)$ & 0.8 & $0.98(0.81-1.18)$ & 0.84 & \\
\hline Infections & $955(0.84)$ & $315(0.82)$ & $0.98(0.86-1.11)$ & 0.72 & $0.98(0.86-1.12)$ & 0.78 & \\
\hline $\begin{array}{l}\text { Urinary/renal } \\
\text { complications }\end{array}$ & $671(0.59)$ & $226(0.59)$ & $1.00(0.86-1.16)$ & 0.97 & $1.01(0.87-1.18)$ & 0.87 & \\
\hline $\begin{array}{l}\text { Pulmonary } \\
\text { complications }\end{array}$ & $1,504(1.33)$ & $567(1.48)$ & $1.12(1.01-1.23)$ & 0.025 & $1.12(1.01-1.24)$ & 0.028 & $649(342-6,193)$ \\
\hline $\begin{array}{r}\text { Gastrointestinal } \\
\text { complications }\end{array}$ & $4,404(3.88)$ & $1.491(3.89)$ & $1.00(0.94-1.06)$ & 0.93 & $1.00(0.94-1.07)$ & 0.98 & \\
\hline $\begin{array}{l}\text { Cardiovascular } \\
\text { complications }\end{array}$ & $641(0.56)$ & $238(0.62)$ & $1.1(0.95-1.28)$ & 0.21 & $1.10(0.94-1.29)$ & 0.22 & \\
\hline Systemic complications & $1,015(0.89)$ & $349(0.91)$ & $1.02(0.90-1.15)$ & 0.77 & $1.02(0.9-1.15)$ & 0.76 & \\
\hline $\begin{array}{l}\text { Any postoperative } \\
\text { complication }\end{array}$ & $8,450(7.45)$ & $2,927(7.64)$ & $1.03(0.98-1.07)$ & 0.22 & $1.03(0.98-1.08)$ & 0.24 & \\
\hline Mortality & $107(0.09)$ & $51(0.13)$ & $1.41(1.01-1.97)$ & 0.043 & $1.37(0.97-1.94)$ & 0.075 & \\
\hline Interventions & $1,184(1.04)$ & $411(1.07)$ & $1.03(0.92-1.15)$ & 0.63 & $1.03(0.92-1.16)$ & 0.56 & \\
\hline Reoperations & $621(0.55)$ & $247(0.64)$ & $1.18(1.02-1.37)$ & 0.029 & $1.21(1.04-1.41)$ & 0.013 & $1,028(531-15,695)$ \\
\hline \multicolumn{8}{|l|}{ Discharge status } \\
\hline Routine & $109,983(96.94)$ & $37,113(96.86)$ & $0.98(0.92-1.05)$ & 0.6 & $0.99(0.91-1.06)$ & 0.73 & \\
\hline Others & $3,474(3.06)$ & $1,204(3.14)$ & Ref. & & Ref. & & \\
\hline
\end{tabular}

Adjustment for: age, gender, insurance, ZIP code-related income, hospital location/teaching status, hospital volume, severity of appendicitis, Deyo score, year of operation

Multivariable regression analysis for retained foreign body was not performed due to limited events

$N N H$ number needed to harm of unadjusted data

[25] and esophageal hemorrhage [14]. Studies of myocardial infarction have shown mixed results: it has been found to be associated with higher mortality on weekends in the United States [7] but not in Japan [26]. That the "weekend effect" is not detectable across all diseases is likely attributable to reasons, such as different baseline patient characteristics, differences in disease mechanism and treatment patterns, and lack of statistical power to detect differences in mortality. However, even more important is the underlying mortality risk for different diseases. In our study, this is less of a concern because patients with acute appendicitis are, on average, young and healthy and the underlying mortality risk is very low.

We were unable to detect significant differences for intra- and postoperative morbidity, except for pulmonary complications. Understaffing and a reduced nurse to patient 
ratio is one of the most discussed reasons for increased complications on weekends [27-29], and this could potentially be responsible for the slightly higher pulmonary complication rate on weekends in our study. However, it must be emphasized that even though the difference was statistically significant due to the very large sample size, the absolute difference of pulmonary complications among weekday and weekend admission was only $0.15 \%$, resulting in a high number needed to harm of 649 . This difference, although statistically significant, is of negligible clinical relevance.

Interestingly, the rate of complicated appendicitis was similar on weekdays and weekends in this study. It has been previously reported that the delay from onset of symptoms to emergency room admission and the delay from admission to treatment is longer on weekends than weekdays $[6,30]$. In relation to acute appendicitis, one should assume that this time delay would result in a higher incidence of perforation and periappendiceal abscess formation. This assumption is supported by several authors reporting that the duration from onset of symptoms to operation is an important timeframe leading to complicated appendicitis [16-18, 31]. However, no such difference was found in the present investigation.

We acknowledge that there are limitations of our study. Due to the administrative nature of the underlying database, it is possible that some diagnoses, procedures, and other variables were miscoded. However, we believe that the miscoding should be nondifferential, i.e., not more common on weekday or weekend. Second, the NIS database offers only inpatient data. Therefore, complications occurring after hospital discharge could not be included in this analysis. Third, we are limited to the variables available in the dataset. Accordingly, we were not able to differentiate between daytime or nighttime admissions, which could impact adverse outcomes. Despite these limitations, our study has important strengths: first, the large sample size enhances the confidence in our results, and second, the population-based nature of this database means that the results have high external validity.

In summary, these analyses provide compelling evidence that there is no clinically significant "weekend effect" for patients undergoing laparoscopic appendectomy for acute appendicitis. This negative finding helps to avoid potentially extensive cost spending to eliminate a clinically insignificant "weekend effect" in a highly prevalent disease. No hospital or staffing policy changes are justified based on the findings from this large national study. Laparoscopic appendectomy for acute appendicitis is not prone to the "weekend effect."

Acknowledgment The authors thank the Research on Research Group (http://researchonresearch.duhs.duke.edu/, last accessed
10/2011) for the research process platforms used in the preparation of our manuscript []. This work was supported by grant PBBEP3-131567 from the Swiss National Science Foundation (MW). The authors have no conflicts of interest, including specific financial interests and relationships and affiliations relevant to the subject matter or materials discussed in the manuscript) $[32,33]$.

\section{References}

1. Hall MJ, DeFrances CJ, Williams SN et al (2010) National hospital discharge survey: 2007 summary. Nat Health Stat Rep 1-20:24

2. DeCoster C, Roos NP, Carriere KC, Peterson S (1997) Inappropriate hospital use by patients receiving care for medical conditions: targeting utilization review. CMAJ 157:889-896

3. Petersen LA, Brennan TA, O'Neil AC et al (1994) Does housestaff discontinuity of care increase the risk for preventable adverse events? Ann Intern Med 121:866-872

4. Hamilton P, Eschiti VS, Hernandez K, Neill D (2007) Differences between weekend and weekday nurse work environments and patient outcomes: a focus group approach to model testing. J Perinat Neonatal Nurs 21:331-341

5. Angus DC, Shorr AF, White A et al (2006) Critical care delivery in the United States: distribution of services and compliance with Leapfrog recommendations. Crit Care Med 34:1016-1024

6. Bell CM, Redelmeier DA (2001) Mortality among patients admitted to hospitals on weekends as compared with weekdays. N Engl J Med 345:663-668

7. Kostis WJ, Demissie K, Marcella SW et al (2007) Weekend versus weekday admission and mortality from myocardial infarction. N Engl J Med 356:1099-1109

8. James MT, Wald R, Bell CM et al (2010) Weekend hospital admission, acute kidney injury, and mortality. J Am Soc Nephrol $21: 845-851$

9. Barba R, Losa JE, Velasco M et al (2006) Mortality among adult patients admitted to the hospital on weekends. Eur J Intern Med $17: 322-324$

10. Dorn SD, Shah ND, Berg BP, Naessens JM (2010) Effect of weekend hospital admission on gastrointestinal hemorrhage outcomes. Dig Dis Sci 55:1658-1666

11. Cram P, Hillis SL, Barnett M, Rosenthal GE (2004) Effects of weekend admission and hospital teaching status on in-hospital mortality. Am J Med 117:151-157

12. Crowley RW, Yeoh HK, Stukenborg GJ et al (2009) Influence of weekend hospital admission on short-term mortality after intracerebral hemorrhage. Stroke 40:2387-2392

13. Magid DJ, Wang Y, Herrin J et al (2005) Relationship between time of day, day of week, timeliness of reperfusion, and in-hospital mortality for patients with acute ST-segment elevation myocardial infarction. JAMA 294:803-812

14. Myers RP, Kaplan GG, Shaheen AM (2009) The effect of weekend versus weekday admission on outcomes of esophageal variceal hemorrhage. Can J Gastroenterol 23:495-501

15. Shaheen AA, Kaplan GG, Myers RP (2009) Weekend versus weekday admission and mortality from gastrointestinal hemorrhage caused by peptic ulcer disease. Clin Gastroenterol Hepatol 7:303-310

16. Ditillo MF, Dziura JD, Rabinovici R (2006) Is it safe to delay appendectomy in adults with acute appendicitis? Ann Surg 244:656-660

17. Sheu BF, Chiu TF, Chen JC et al (2007) Risk factors associated with perforated appendicitis in elderly patients presenting with signs and symptoms of acute appendicitis. ANZ J Surg 77: 662-666 
18. Kearney D, Cahill RA, O'Brien E et al (2008) Influence of delays on perforation risk in adults with acute appendicitis. Dis Colon Rectum 51:1823-1827

19. Stahlfeld K, Hower J, Homitsky S, Madden J (2007) Is acute appendicitis a surgical emergency? Am Surg 73:626-629 (discussion 629-630)

20. Abou-Nukta F, Bakhos C, Arroyo K et al (2006) Effects of delaying appendectomy for acute appendicitis for 12 to 24 hours. Arch Surg 141:504-506 (discussion 506-507)

21. Guller U, Hervey S, Purves H et al (2004) Laparoscopic versus open appendectomy: outcomes comparison based on a large administrative database. Ann Surg 239:43-52

22. http://www.hcup-us.ahrq.gov/nisoverview.jsp. Overview of the Nationwide Inpatient Sample (NIS). Accessed 4 March 2012

23. Deyo RA, Cherkin DC, Ciol MA (1992) Adapting a clinical comorbidity index for use with ICD-9-CM administrative databases. J Clin Epidemiol 45:613-619

24. Charlson ME, Pompei P, Ales KL, MacKenzie CR (1987) A new method of classifying prognostic comorbidity in longitudinal studies: development and validation. J Chronic Dis 40:373-383

25. Crowley RW, Yeoh HK, Stukenborg GJ et al (2009) Influence of weekend versus weekday hospital admission on mortality following subarachnoid hemorrhage. J Neurosurg 111:60-66
26. Matsui K, Kojima S, Sakamoto T et al (2007) Weekend onset of acute myocardial infarction does not have a negative impact on outcome in Japan. Circ J 71:1841-1844

27. Tarnow-Mordi WO, Hau C, Warden A, Shearer AJ (2000) Hospital mortality in relation to staff workload: a 4-year study in an adult intensive-care unit. Lancet 356:185-189

28. Cho SH, Hwang JH, Kim J (2008) Nurse staffing and patient mortality in intensive care units. Nurs Res 57:322-330

29. Needleman J, Buerhaus P, Mattke S et al (2002) Nurse-staffing levels and the quality of care in hospitals. N Engl J Med 346: $1715-1722$

30. Clark K, Normile LB (2007) Influence of time-to-interventions for emergency department critical care patients on hospital mortality. J Emerg Nurs 33:6-13 (quiz 90)

31. Hansson LE, Laurell H, Gunnarsson U (2008) Impact of time in the development of acute appendicitis. Dig Surg 25:394-399

32. Shah J, Shah A, Pietrobon R (2009) Scientific writing of novice researchers: what difficulties and encouragements do they encounter? Acad Med 84:511-516

33. Pietrobon R, Guller U, Martins H et al (2004) A suite of web applications to streamline the interdisciplinary collaboration in secondary data analyses. BMC Med Res Methodol 4:29 